Розин В.M.

\title{
Студия музыкального движения и импровизации «Гептахор» - коллективный автор нового вида искусств
}

Аннотация: В статье автор делится своими наблюдениями от спектакля студии «Гептахор». Наряду с сильным впечатлением от увиденного он ставит три проблемы, касающиеся восприятия и понимания жанра музыкального движения. Высказывает гипотезу, что зрители в данном случае встретились с новым видом искусства. Дальше эта гипотеза разъясняется и обосновывается. Главными темами при этом выступают: объяснение особенностей музыкального движения, проблема формирования новой художественной формы, анализ музыкальной реальности, которая складывается в жанре музыкального движения, роль осмысления и интерпретаций музыкальных произведений, выслушиваемых музыкальным движением. В результате проведенного исследования автор укрепляется в высказанной им гипотезе. В данном исследовании были реализованы идеи гуманитарного и герменевтического подходов, предложены авторские интерпретации пластических спектаклей - «Рождение солнца» на музыку балета И.Стравинского «Весна священная» и «Принцип Аполлона» на музыку того же композитора «Аполлон Мусагет»; в целом автор работал в русле развиваемой им гуманитарной методологии. В результате проведенного исследования ему удалось показать, что, действительно, складывается новый вид искусства, в чем особенности музыкального движения как нового вида искусства, как в рамках музыкального движения становится и формируется новая художественная форма и реальность, какие интеллектуальные и духовные условия поддерживают это становление.

Ключевые слова: Музыка, движение, спектакль, эстетика, личность, интерпретация, произведение, балет, танцы, музыкальное движение.

Review: In the article the author shares his observations on the performance studio "Heptahor". Along with the strong impression from what he saw, he raises three issues relating to the perception and understanding of the genre of musical movement. It is hypothesized that the audience in this case met with a new kind of art. Further, the hypothesis explained and justified. The main themes are: explanation of features of musical movement, creation of a new art form, analysis of the musical reality that is emerging in the genre of musical movement, role of comprehension and interpretation of music played to the musical movement. As a result of the study the author proves his hypothesis. In his study Rozin introduces the ideas of humanitarian and hermeneutical approaches and offers his own interpretations of the plastic performances 'The Birth of the Sun' after Igor Stravinsky's ballet 'The Rite of Spring' and 'Apollo's Principle' after Igor Stravinsky's ballet 'Apollon Musaget'. In general, the author continues to develop his humanitarian methodology. As a result of the research the author has been ablel to demonstrate that it was indeed a new art form, to describe features of the musical movement as a new art form, how a new art form and reality have been developed within the framework of the musical movement and what intellectual and spiritual grounds supported that development.

Keywords: Ballet, work, interpretation, personality, aesthetics, performance, movement, music, dance, musical movement.

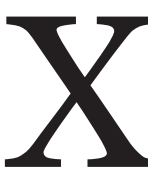

удожественный руководитель студии Аида Айламазян пригласила меня на очередной спектакль 13 мая этого года. В уютном театре «Малая драматическая труппа», который действует при «Центре культуры и спорта» ГБУК г. Москвы, зрители посмотрели два пластических спектакля: «Рождение солнца» на музыку балета И. Стравинского «Весна священная» и «Принцип Аполлона» на музыку того же композито- ра «Аполлон Мусагет». Музыкальное действо группы Аиды далеко и от традиционного балета и от танца в обычном понимании. Внешне движения и одежда исполнителей спектакля заставляют вспомнить Айседору Дункан. Впрочем, именно ее танцы инициировали создание в далеком прошлом студии «Гептахор», а сама Аида, так сказать, «наследница по прямой», музыкальному движению она училась у Ольги Кондратьевны Поповой, 
ученицы и сподвижницы основателя «Гептахора» Стефаниды Рудневой (Студия была создана в Петербурге в 1914 г. Рудневой и её подругами - Н. А. Энман, Н. В. Педьковой, К.В. Тревер, И. В. Тревер, Е. В. Цинзерлинг и Ю. В. Тихомировой, которые все были студентками Бестужевских курсов). Тем не менее, нельзя сказать, что увиденное в театре - это вариации или коллективное расширение танцев Дункан, ни в коем случае, зрители встретились с настоящим новым видом искусства. Понимаю, что мое заявление ответственное новый вид искусства, не более и не менее, но я готов разъяснить и доказывать.

Сначала расскажу о замеченных на спектакле и удививших меня трех моментах. В программе спектакля изложены довольно подробно либретто «Принципа Аполлона» (я приведу из него только начало) и относительно кратко пояснение к «Рождению солнца», (его я процитирую целиком). «“Аполлон Мусагет”. Либретто: 1. Рождение Аполлона. Таинственно появление бога. Оно предопределено, а поступь его звучит как призыв, как властное требование, как напряжение всех сил души. Символами и воплощением идеи являются струны лиры Аполлона, соединяющие небо и землю и послушно воспевающие бога, творящего гармонию... "Весна священная”. Движение выявляет музыкальную драматургию. Смена коротких тем-попевок звучит как диалог. Отсутствие внешнего развития вызывает нагнетание изначального состояния, которое заканчивается “взрывом": бешеный яркий ритм музыки как бы высвобождает спящие до поры силы. Ритмическая непредсказуемость музыки отражает стихийное ощущение жизни и присутствие в ней сверхчеловеческой мощи. Условный сюжсет построен на музыкально-пластических образах, рожденных в процессе совместной импровизации. Это перекличка земных и небесных сил, людей и стихий, их единение. Четырежды рождается “солнце”, и только последнее усилие, последняя “жертва” освобождает его животворящую силу. Победно вращается колесо - символ огня и жизни».

Меня давно интересовала роль подобных программ. Дело в том, что, как правило, представленный в них рассказ (либретто, сюжет, фабула) практически невозможно соотнести с тем, что происходит на сцене. И в данном случае, хотя я внимательно прочел программу до начала спектакля, но как только он начался, тут же все благополучно забыл. «Рож- дение солнца» настолько захватило меня, что было бы странным сверять музыкальное действо с «дорожной картой», намеченной в программе. Правда, когда я смотрел и слушал «Принцип Аполлона», то пару раз заглянул в программу, но, во-первых, на ходу не смог отождествить события, во-вторых, понял, что этот поиск отвлекает от спектакля. В то же время, я понимаю, что программы для чего-то нужны, но спрашивается, для чего? Это первый момент.

Второй такой. Во многих местах (мизансценах) спектакля в глаза бросалось как бы внешнее несоответствие музыки и пластических образов. Музыка, естественно, не прекращается, движется, а танцоры застыли неподвижно или очень медленно двигаются, явно не в том ритме и темпе. При этом за счет поз исполнителей, их расположения, действий образуется сложный рисунок, даже визуальная структура, которая, как ни странно, не только не мешает музыке, но, наоборот, ее выявляет и выражает. Это формальное, очевидное противоречие меня поразило.

Третий момент. Несмотря на указанное противоречие, я впервые, вдруг, услышал Игоря Стравинского. Он не мой композитор, и честно говоря, его музыка меня никогда не волновала и не задевала в отличие, скажем, от Прокофьева или Шостаковича. А тут на спектакле, где вроде бы главное - не музыка, а музыкальное движение, недаром спектакль назван «пластическим», я не только следил за танцем, жил им, но и услышал музыку Стравинского, да так рельефно, ярко; она мне показалась удивительно сильной и красивой. А ведь я всегда воспринимал его музыку, как формальную, запутанную, искусственную.

Но я бы не стал особенно противопоставлять музыку спектакля и пластические построения, в которых узнавались то языческие, то древнеегипетские, то античные визуальные образы и архетипы. Общее впечатление было такое, что меня вовлекли в мир музыкальных духов, муз и богов, в мистерию прошлого, но и в настоящую - ну, если и не мистерию, то художественную лабораторию, где на моих глазах танцоры, босые прекрасные девушки в одеяниях, напоминающих древнегреческие туники, ткали полотно художественного действа. Это так сказать, внешние впечатления. Теперь теоретические размышления и соображения.

Первый уровень обсуждения будет отчасти формальный, близкий к искусствоведческому 
подходу. Почему разработки и спектакли студии «Гептахор», а я за ними слежу с самого начала творчества этой группы, можно отнести к новому виду искусств? Ну, во-первых, они не похожи на другие виды искусств: как уже отмечалось, на классический балет, на народные танцы, не похожи и на другие виды свободного танца, идущие от Дункан. Во-вторых, благодаря усилиям Аиды Айламазьян, музыкальное движение постоянно осмысляется, в результате налицо работа по выделению «выразительных средств» $[1 ; 2 ; 3 ; 4]$. Но известно, что выделение и описание выразительных средств является одним из показателей формирования нового вида искусства. В-третьих, уже вполне можно говорить о воспроизводстве художественной практики студии «Гептахор». Практически все продвинутые участники студии передают опыт музыкального движения, ведут группы, в том числе детские. Еще один показатель не так просто пояснить - спектакли студии в последние годы часто воспринимаются как «чистое искусство». По аналогии с жанрами инструментальной музыки (например, сонатами и симфониями) или балетом музыкальные спектакли студии не требуют опоры на внемузыкальные средства (слово, пение, разъяснение), они обладают внутренней логикой, понимаются и переживаются как бы сами по себе.

Второй уровень я бы назвал содержательным и психолого-семиотическим в духе M.M. Бахтина, когда тот писал, что нужно «войти творцом в видимое, слышимое, произносимое и тем самым преодолеть материальный внетворчески-определенный характер формы... - художник, утверждает Бахтин, - «становится активным в форме и формой занимает ценностную позицию ...» [5, с. 5859]. Для меня данный подход предполагает обсуждение двух основных тем: создание художником новой формы, которая и выступает условием формирования нового вида искусства, и построение и становление новой художественной реальности как второго необходимого условия.

В случае с музыкальным движением новая художественная форма создается, с одной стороны, на основе особого типа соединения музыкальной и танцевальной (пластической) форм и построений, с другой - с помощью интерпретации и сценирования содержания музыкального произведения. Способ соединения в музыкальном движения построений и форм задается не установками на «изображение» музыки (как в балете) или «выражение» себя в музыке, а задачей «выслушать музыку музыкальным движением», «прожить ее в такой форме». Что это означает? На мой взгляд, по отношению к музыкальной форме - необходимость увидеть и реализовать ее в форме музыкального, пластического движения, что ведет к новой организации музыкальной формы. Именно эта организация бросалась мне в глаза, когда я замечал несоответствие музыкальных и пластических образов («малых форм»). Можно ли сказать - и наоборот, т.е. необходимость услышать музыкальные движения в форме музыки. И да и нет. Да, поскольку пластическим движением выслушивается и проживается музыка. Нет, так как нужно создать новую организацию музыкального потока, а для этого требуется организовать конфликт музыкальной и пластической форм.

Построение «крупной формы» в масштабе произведения предполагает создание особой интерпретации (интерпретаций), которая работает в роли своеобразного «эпистемически-образного моста», соединяющего структуру музыкального произведения (в данном случае музыку балетов Стравинского) с пластическими образами и переходами между ними. Собственно содержание программы спектакля, на мой взгляд, на 90\% представляет собой подобную интерпретацию, адресованную зрителю. Но значительно важнее ее роль для постановщика спектакля (Аиды) и его исполнителей. Как я показываю в своих работах, подобные интерпретации создаются на основе нарративных или графических «схем». Схемы как методологическое понятие, а не просто текст, вводятся мною, чтобы объяснить, каким образом проблемы, стоящие перед человеком, могут быть разрешены им за счет такого семиотического (нарративного или графического) построения, которое задает новую реальность и видение (например, мы начинаем видеть музыкальные события «Весны священной» посредством музыкально-пластических образов), и поэтому получаем возможность по-новому действовать (выстраивать спектакль) [6].

В одной беседе Аида рассказала мне, как она создавала интерпретацию для большой и малых форм «Поэмы экстаза» Скрябина, которая была с большим успехом исполнена группой музыкального движения совместно с группами свободного танца в 2005 году в зале им. Чайковского. «Когда я искала “ход” к 
Скрябину, - пишет Аида, - то на самом деле решала ряд задач (т.е. проблем, для разрешения которых создаются схемы. - B.P.). Это действительно “ход”, то есть нужно было найти некую идею, которая бы позволила все эти задачи “собрать”, как-то одним махом связать. Во-первых, надо было отнестись к известным Скрябинским идеям цветомузыки; во-вторых - к его поэтическому тексту, посвященному “Поэме экстаза"; в-третьих, разобраться с существующими трактовками музыки Скрябина. Одновременно надо было решать собственные задачи: 1) объединить группы разных направлений свободного танца в совместном действе; 2) не нарушать принципы музыкального движения - слияния с музыкой, проживания музыки, импровизационность танца, живое присутствие участников “здесь и теперь”, реальность их переживаний. Один из принципов связан с тем, что музыка изначально берется импровизационно, и потом в совместной работе рождается музыкальнодвигательная форма, композиция. Но в этой ситуации у меня были разные группы, множество участников, несовпадающие принципы работы и т.п.. Да и музыка была слишком грандиозной, сложной, это большое симфоническое произведение и опыта таких постановок у групп - участников проекта не было.

Попытки воплотить музыку Скрябина визуально конечно были, но следует обратить внимание на сам подход - именно в цвете на экране (то есть на плоскости ) построить визуальный ряд. Мне сам подход представляется неверным, потому что цветовая музыка Скрябина - это конечно не плоскость и не экран. Я поняла, что технически задачи цветомузыки с трудом решаются или решаются прямолинейно, с утратой сквозного музыкального содержания, эти соображения побудили меня отказаться от идеи цветомузыки, и я постаралась как бы забыть об этом. Познакомившись с текстом Скрябинских стихов, я поняла, что лучше забыть и об этом, просто потому что это плохие стихи, а значит не стоит им слишком доверять. Скрябинская музыка несопоставима с ними. Однако сам факт построения текста я сочла важным, так же как и то, что Скрябин строил философские системы, и, по всей видимости, я стала искать в его музыке воплощения неких философских доктрин. И здесь на этой почве музыка Скрябина увиделась совсем не импрессионистичной, как ее описывают многие музыковеды, а довольно концептуальной и символичной. Так удалось выско- чить из размыто-размазанного восприятия музыки Скрябина, лишенного сильной формы и завершенности высказывания. Именно прочувствованный вдруг интеллектуализм Скрябина дал ключ к решению и какие-то открыл шлюзы, освобождавшие от стереотипов, от известных мнений и подходов.

В случае со Скрябиным пришел не миг, не отдельный фрагмент или какое-то ощущение, а вдруг увиделось целиком все произведение как ясно развернутое, последовательное движение мысли, как символическое выражение некоторых теософских (и не только теософских) идей, как очень продуманная и точно просчитанная музыкальная форма, имеющая четкую структуру (в моей версии, Аида вышла на «большую форму». - B.P.). И вот эта структура была услышена и обозначена (в предварительных схемах. - B.P.), хотя в то время я еще не знакомилась с партитурой “Поэмы экстаза”. А эта структура оказалась удивительно подходящей к поставленной задаче - включить разные группы в действие, так как явственно выделялись отличающиеся по характеру темы и части, несущие очевидно разные энергии и духовные содержания. Сопоставление этих энергий, представляющих в целом универсум космических и духовных сил, с танцем, с движением, свойственным разным направлениям, неожиданно открыло, что свободный танец в его разнообразных проявлениях, замыслах и опытах также представляет этот универсум человеческого, а может быть и не только человеческого бытия. Идея была найдена. И тогда подумалось, вернее, почувствовалось, что живое выражение этих стихий, присущих каждому из представленных направлений (музыкальное движение, ритмика, Алексеевская гимнастика, эвритмия, буто) в их борьбе и слиянии, противопоставлении и взаимодополнении будет реальным действом, что даст ощущение мистерии как здесь совершающегося события - события объединения людей в танце.

Цветовое решение естественно вытекало из общей концепции: каждой теме как стихии предлагается свой цвет. Соответственно, вместо мелькания цветовых пятен и лампочек, внятное цветовое решение тем и соответственно их музыкальное переплетение должно было дать и цветовые комбинации. И все-таки акцент делался на пластику и выразительность движения, костюм подчинялся движению, обыгрывал его. Поэтому, кстати, полуобнаженные, вымазанные в глине танцоры буто мне показались уместными. Предель- 
ная телесность, плотность их танца не нуждается в летучих элементах одежды, не нуждается в прикрытии.

О приемах работы в процессе создания композиции. Моя работа состояла в том, что я предложила концепцию, которая заразила участников. Надо было, чтобы они приняли свою задачу, увидели свою тему в общей структуре, в совокупности и последовательности других тем, соответственно выстроили свое взаимодействие с другими участниками, осознали свою судьбу внутри данного музыкального произведения. А дальше внутри своих тем и частей они могли работать самостоятельно (что и было сделано) - с последующим обсуждением и коррекцией, прежде всего обусловленной необходимостью создать целостность, выстроить общее взаимодействие, проставить ключевые акценты в общей музыкально-пластической драматургии. И еще раз подчеркну, что мы искали смысловые линии движения групп, а не создавали визуальные картинки. Зрелищность как вторичный феномен возникала просто потому, что люди (то есть зрители) понимали, что перед ними происходит» (приведенный здесь текст написан Аидой Айламазьян по просьбе автора).

Для того чтобы сделать следующий важный шаг, расскажу, каким образом в соответствии с моими исследованиями создается и становится новая художественная реальность. Вопервых, что это такое? Опуская сложности, художественную реальность можно охарактеризовать следующим образом. Это мир событий, который, с одной стороны, создается человеком (например, он пишет музыку балета или ставит пластический спектакль на эту музыку), с другой - может в этом мире полноценно жить и решать свои проблемы, с третьей стороны, это особый мир, не совпадающий с обычным, оцениваемый и переживаемый человеком как прекрасный, страшный, удивительный и прочее (Бахтин говорил здесь об эстетике, но не традиционной, а как особой духовной практики и ценностях жизни). Приведу две иллюстрации: реакцию Святослава Рихтера на музыку Прокофьева, из которой видно, насколько полноценно и ценностно-экстатически композитор (человек) может жить в музыке, и воспоминание Ольги Кондратьевны Поповой, у которой Аида училась, показывающее, что становление художественной реальности позволяет разрешить экзистенциальные проблемы личности и дает ей возможность жить.
«Одно из сильнейших впечатлений, - вспоминает Рихтер, - было от исполнения его Третьей симфонии в 1939 году. Дирижировал автор. Ничего подобного в жизни я при слушании музыки не ощущал. Она подействовала на меня как светопреставление. Прокофьев использует в симфонии сверхинтенсивные средства выражения. В третьей части, скерцо, струнные играют такую отрывистую фигуру, которая как бы летает, точно летают сгустки угара, как если бы что-то горело в самом воздухе. Последняя часть начинается в характере мрачного марша - разверзаются и опрокидываются грандиозные массы - «конец вселенной», потом после некоторого затишья все начинается с удвоенной силой при погребальном звучании колокола. Я сидел и не знал, что со мной будет. Хотелось спрятаться. Посмотрел на соседа, он был мокрый и красный... В антракте меня еще пробирали мурашки» [8, с. 459]. А когда Гульд слушал Шуберта в исполнении Рихтера, то был в состоянии, как он выразился, близком к гипнотическому трансу [9].

«Я была, - вспоминает Попова, - ребенком страшной психической отзывчивости. <...> Очень легко было дойти до чего угодно, потому что моя психика была очень чувствительна, ранима, и жизнь такая, что... Я очень долго думала, и все года эти, и предыдущие (девочки <ученицы> знают), я часто спрашивала себя: что музыкальное движение дало мне - поддержку? или наоборот? И только сейчас я могу с абсолютной уверенностью сказать: если б не было музыкального движения, я могла бы дойти до любой степени психической болезни. Абсолютно точно. Что это такое? А это способность какие-то все нереализованные свои переживания, и может быть, эту жизнь всю... вылить. Мне дается реальная возможность высказаться. Вылить, не в себе держать все это, не давить и переживать молча, а мне дается моторный путь в этой деятельности пережить... Ведь я опять повторяю: мы не замахиваемся, что я танцую точно Баха - да в жизни этого не будет! Я танцую свою идею в Бахе, да? Свое переживание. И в этот момент, видно, реализовываются такие состояния и такие настроения, которые иначе я бы имела у себя в душе навечно. И они бы меня постепенно убивали. То есть, видно, эта деятельность - это какой-то мощный прорыв и поток, который я из себя выпускаю. Сейчас я в этом убеждена глубоко. Это возможность жить. И возможность регулировать свои состояния» [4]. 
Чтобы понять, каким образом художественная реальность формируется, рассмотрим один кейс, а именно открытие маленьким ребенком изображения. Вот взрослый рисует на бумаге красное круглое пятно и говорит, показывая на него: смотри Маша, какое солнышко. Но оказывается, что сначала Маша никакого солнца не видит. Кстати, понятно почему: солнышко на небе, светит, слепит, греет, а тут бумага и красное пятно. Однако потом, почему-то Маша начинает видеть на бумаге солнышко.

Подтолкнуть к этому открытию могла, например, следующая сцена. Вечером, на закате отец Маши показывает ей солнце и говорит: как красиво, солнце садится. Неожиданно Маша замечает, что солнце на закате очень даже похоже на красное круглое пятно. А дальше происходит то, что можно назвать «сдвигом на форму». С одной стороны, рисуя красное круглое пятно, Маша смотрит на него, вспоминая солнце на закате. С другой - «красное пятно на фоне белой бумаги» она начинает воспринимать как солнце, но такое, которое не на небе, не слепит и не греет, но которое зато можно создать самой (нарисовать), причем так, как хочется и для интересного времяпрепровождения. Например, нарисовать красное пятно и сказать, что солнышко пришло к Маше, оно будет греть травку, ходить по небу и пр. В данном случае роль «рисуночного солнышка» не в том, чтобы реально быть на небе, светить и греть, а в том, чтобы Маше играть и говорить, чтобы общаться по поводу солнышка, чтобы жить в этом новом интересном мире.

Обобщая этот пример (естественно привлекая и другие), можно ввести такие различения. Во-первых, существуют экзистенциальные проблемы индивида, требующие своего разрешения. Конкретно для Маши, когда она еще не познакомилась с изображением, это желание увидеть солнце на бумаге, которого она не видит, хотя ее папа почему-то видит. Подобное желание очень естественное и важное для ребенка. Живя вместе с родителями, не отделяя себя от них, что Л.С. Выготский обозначал термином «прамы», маленький ребенок стремится соответственно и жить (видеть, слышать, чувствовать то, что говорят родители; уж если папа говорит, показывая на красное пятно - это солнышко, то оно там обязательно должно быть). Во-вторых, есть такой феномен как обнаружение новой формы (солнца на закате, красного пятна на фоне бумаги), которое в семиотическом плане может быть понято как схема. Новая форма, что следует из дальнейших событий, позволяет справиться с экзистенциальной ситуацией (увидеть солнце на бумаге), открывает новое видение (изображение предмета в рисунке), позволяет по-новому действовать (общаться и играть на основе изображения).

Одно из условий изобретения схемы «сдвиг на форму», когда индивид осознает особенности самой формы или ее построения (не солнце и красное пятно, а солнце на фоне неба, круглое красное пятно, нарисованное на бумаге). Другое необходимое условие - обнаружение новой предметности (в данном примере, открытие рисуночного солныцика, оно живет не на небе, а на бумаге, не светит и не греет, его можно нарисовать, с ним интересно играть и прочее). Что значит в данном случае «обнаружение»? В психологическом плане, вероятно, переорганизация на основе творческого усилия и схемы психического опыта индивида, а также акт осознания существования, реальности (естественно в том виде и форме, которые для него доступны). Без осознания рисуночного солнышка, т.е. обнаружения его в мире, именования (на эту необходимость указывал еще Платон), осознания его отличия от родственных предметов (рисуночное солнышко чем-то отличается от обычного солнца) - новая предметность появиться не может. Другое дело, непросто объяснить, каким образом индивид выражает все эти аспекты становления новой предметности.

Еще одно условие, точнее предпосылка - включение в новое целое (переключение целого). Действительно, чтобы Маша смогла открыть рисуночное солнышко и начать с ним жить (рисовать, играть, общаться по его поводу с другими), она должна была переключиться на проблему взаимоотношения с отцом (раз он говорит солнышко, то так и должно быть; здесь существование и коммуникация в рамках прамы совпадают), на ситуацию любования закатом (тоже, кстати, интерсубъективную, поскольку требует отклика), на реальность игры и общения. Все перечисленные здесь моменты и образуют основу для формирования новой художественной реальности, позволяющей индивиду разрешать определенные экзистенциальные ситуации и полноценно жить.

Взглянем с точки зрения этих различений на творчество студии «Гептахор». Прежде 
всего, стоит обратить внимание на объемлющее целое. Им является характерное для участников студии мироощущение, а также культивируемые и практикуемые ими образ и стиль жизнь. Для мироощущения гептахорцев характерны такие идеи как противостояние ценностям и механичности современной жизни, где деньги, комфорт, успех, карьера, развлечения вытесняют все остальное. И такая идея как здоровый, нравственный образ жизни. Жизнь общением и танцем. И почти эзотерическая идея - «пути жизни». В принципе свободным танцем они занимаются не для сцены, прекрасного или даже творчества (хотя эти моменты сопровождают свободный танец). Освоение и занятие музыкальным движением - это форма, образ и стиль жизни, позволяющие личности реализовать себя, найти себя в этом пошатнувшемся мире, почувствовать человеком, опереться на помощь друзей и соратников по жизненному пути. Это также ощущение другого прекрасного мира, в который, если трудиться, можно пройти, который можно почувствовать и про-жить. Переключение на это целое, задающее для гептахорцев и их зрителей экзистенциальные проблемы, и выступило одной из важнейших предпосылок становления нового вида искусства.

Вторая предпосылка и условие - изобретение новой художественной формы. Здесь главным было, с одной стороны, соединение серьезной музыки и свободного танца, позволяющее выслушать музыку движением, прожить ее по-новому, с другой - создание новых интерпретаций музыкальных и танцевальных произведений. Нельзя сказать, что подобные интерпретации не создаются постановщиками других видов искусства. Но важно, что они стали разрабатываться для произведений, которые ставились на основе музыкального движения. Кроме того, но возможно, я ошибаюсь, Аида опирается в этой работе на опыт современной гуманитарной методологии.

Новый вид искусства не состоялся бы и без открытия новой художественной предметности - собственно музыкального движения. Его характеристики довольно парадоксальные. Это и танец и не танец, музыка, протекающая в пластике сменяющих друг друга языческих и античных образов, и не музыка. Произведение искусства и действие, не относящееся к искусству. Техника и своеобразный профессионализм и свободное не- техническое творчество и дилетантство. Если опираться на разобранный выше кейс, то нужно утверждать, что предметность музыкального движения складывалась на основе предметности чистой (инструментальной) серьезной музыки и предметности свободного танца, причем объемлющим целым, задающим экзистенциальные проблемы, выступали мироощущение и образ жизни гептахорцев. Трудно сказать, какие именно характеристики свободного танца и чистой музыки выпали в предметности музыкального движения, а какие были привнесены новыми функциями. Отчасти это зависело от того, каким образом личность осваивала музыкальное движение. Тем не менее, понятно, чтобы выяснить особенности формирования предметности музыкального движения, требуются специальные исследования, опирающиеся на реальный опыт этого вида художественной практики.

Почему я вдруг услышал музыку Стравинского? Не только потому, что музыкальное движение переорганизовало для меня привычный музыкальный поток, помогло создать новую музыкальную форму, без этого, конечно, я бы эту музыку так и не услышал. Но также и потому, что гептахорцы погрузили меня в новый мир, создали музыкальным движением такое объемлющее целое, где возникли условия для актуализации у меня новых экзистенциальных проблем. И оказалось, что именно музыка Стравинского, но выслушанная музыкальным движением, обеспечивает разрешение этих проблем.

Почему я забыл об интерпретациях Аиды и был полностью поглощен разворачивающимся на сцене художественным действом? Вероятно, потому, что спектакль был выстроен и исполнен так, что позволял зрителю полноценно жить в предъявленной новой предметности, которая, замечу, не создается без активного участия зрителя. Однако вряд ли бы это произошло, если бы я попал на представление студии впервые. Вспоминаю ранние выступления и спектакли. Многие из них воспринимались еще как эксперименты, не захватывали. Пожалуй, впервые ощущение подлинной реальности у меня возникло только на спектакле студии «Орфей и Эвридика» по музыке Глюка. Очевидно, необходимо все же освоить язык музыкального движения, проникнуться атмосферой нового креативного действа, испытать на себе влияние гептахорцев, самому пойти навстречу. 


\section{Библиография:}

1. Айламазьян А.М. Есть ли будущее у школы Дункан // Журнал практического психолога. 2003 . № 3. C. 181-187.

2. Айламазьян А.М. О механизмах музыкального переживания // Вопросы психологии. 2013. № 5. С. 35-43.

3. Айламазьян А.М. Движение, подчиненное музыке (психолого-феноменологическое исследование) // Культура и искусство. 2016. № 1. С. 96-115.

4. Айламазьян А.М., Ташкеева Е.И. Музыкальное движение: педагогика, психология, художественная практика // Культура и искусство. 2014. № 2. С. 206-244.

5. Бахтин М. Вопросы литературы и эстетики. М., 1975. 504 с.

6. Розин В.М. Введение в схемологию: схемы в философии, культуре, науке, проектировании. М., 2011. $256 \mathrm{c}$.

7. Розин В.М. Природа свободного танца (на материале анализа танцевального действа «Поэма экстаза» // Философия и культура. 2009. № 12. С. 62-73.

8. Прокофьев С.С. Материалы. Документы. Воспоминания. М., 1961. 708 с.

9. Тина Гай Двойники: Рихтер - Гульд http://sotvori-sebia-sam.ru/svyatoslav-rixter/

\section{References (transliterated):}

1. Ailamaz’yan A.M. Est’ li budushchee u shkoly Dunkan // Zhurnal prakticheskogo psikhologa. 2003 . № 3. S. 181-187.

2. Ailamaz'yan A.M. O mekhanizmakh muzykal'nogo perezhivaniya // Voprosy psikhologii. 2013. № 5. S. $35-43$.

3. Ailamaz'yan A.M. Dvizhenie, podchinennoe muzyke (psikhologo-fenomenologicheskoe issledovanie) // Kul'tura i iskusstvo. 2016. № 1. S. 96-115.

4. Ailamaz'yan A.M., Tashkeeva E.I. Muzykal'noe dvizhenie: pedagogika, psikhologiya, khudozhestvennaya praktika // Kul’tura i iskusstvo. 2014. № 2. S. 206-244.

5. Bakhtin M. Voprosy literatury i estetiki. M., 1975. 504 s.

6. Rozin V.M. Vvedenie v skhemologiyu: skhemy v filosofii, kul'ture, nauke, proektirovanii. M., 2011.256 s.

7. Rozin V.M. Priroda svobodnogo tantsa (na materiale analiza tantseval'nogo deistva «Poema ekstaza» // Filosofiya i kul’tura. 2009. № 12. S. 62-73.

8. Prokof'ev C.S. Materialy. Dokumenty. Vospominaniya. M., 1961. 708 s.

9. Tina Gai Dvoiniki: Rikhter - Gul'd http://sotvori-sebia-sam.ru/svyatoslav-rixter/ 